\title{
Dietary Intake Patterns and Prevalence of Anaemia in Adolescents
}

\author{
Manjot Kaur ${ }^{1}$ and Meenu Aggarwal ${ }^{2 *}$ \\ ${ }^{1}$ Indira Gandhi National Open University, Shyama Prasad Mukherji College for Women, University of Delhi, India \\ ${ }^{2}$ Associate Professor, Shyama Prasad Mukherji College for Women, University of Delhi, India
}

*Corresponding author: meenuag63@gmail.com

\begin{abstract}
This study was conducted on 100 adolescents residing in Delhi. They belonged to high socio-economic strata. Dietary intake patterns of subjects revealed low intake of iron rich foods. Green leafy vegetables consumption was also very low. It was also observed that 37 percent adolescents were in habit of skipping meals and 12 percent were in habit of eating junk foods daily. Mean intake of all nutrients (calories, proteins and iron was lower than RDAs. There were no economic constraints still intake of nutrients was deficient due to faulty eating habits. Nutrient Adequacy Ratio (NAR) was not adequate in 81 percent subjects. Only 23 percent subjects were non anaemic and rest had mild or moderate anaemia. Impact of anaemia could be seen in terms of non-participation of anaemic subjects in sports in school and their feeling lethargic.
\end{abstract}

Keywords: Anaemic, Dietary, adolescents, junk foods, NAR

Adolescents are very important section of society. Adolescents aged between 10-19 years account for more than one fifth of the world's population. In India this age group forms 21.4 per cent of total population (Prabhakaran, 2003).

This phase is considered especially nutritionally vulnerable period of life for several reasons. There is greater demand of nutrients due to dramatic increase in physical growth and development. In adolescents there is tremendous change of life-style and food habits, which affect both nutrient intake and needs (Kakkar et al. 2005).

In high socio-economic group strata there are no economic constraints, but various factors like convenience, traditional practices, environment, and ignorance about nutritional requirements, hygiene, sanitation and dietary beliefs appear to influence the dietary intake patterns of adolescents thus affecting their nutritional status. Sociocultural influences are known to affect adolescent eating patterns and behaviors. Teens require increased nutrients to provide for the accelerated growth that takes place during these years.

Adolescents are susceptible to iron deficiency anaemia in view of the increased need for dietary iron for haemoglobin and myoglobin when blood volume and muscle mass are increasing. This risk of anaemia is due to growth spurt and in girls it remains as such during their reproductive life.

This study was conducted to get information on the dietary intake patterns and prevalence of anaemia in adolescents (10-17 years) belonging to high socio economic strata. 


\section{METHODOLOGY}

A pre-coded, pretested and semi structured interview schedule was administered to subjects and their parents to collect information about their socioeconomic background and dietary behavior. Dietary intake of subjects was collected by 24 hours dietary recall and Food frequency method. Haemoglobin estimations were used to find out prevalence of anaemia. WHO classification was used for interpreting results of haemoglobin estimations (WHO, 2001). Factors influencing anaemia were analyzed with help of appropriate statistical tools.

Socio Demographic profile of subjects: The study was conducted on 100 adolescents belonging to high socio economic strata residing in central Delhi. They were 10 to 17 years old, 46 boys and 54 girls participated in the study.

Table 1: Age and gender wise distribution of subjects

\begin{tabular}{llll}
\hline $\begin{array}{l}\text { Age } \\
\text { (years) }\end{array}$ & $\begin{array}{l}\text { Boys } \\
\text { n (\%) }\end{array}$ & $\begin{array}{l}\text { Girls } \\
\text { n (\%) }\end{array}$ & $\begin{array}{l}\text { Total } \\
\text { N }\end{array}$ \\
\hline $10<=12$ & $18(39.0)$ & $25(46.0)$ & 43 \\
$13<=15$ & $16(34.0)$ & $19(35.0)$ & 35 \\
$16<=17$ & $12(26.0)$ & $10(18.0)$ & 22 \\
Total & 46 & 54 & 100 \\
\hline
\end{tabular}

Most $(83 \%)$ of the fathers of subjects were graduates or professionally qualified. They were in service $(36 \%)$, business $(42 \%)$ or working as professionals $(22 \%)$. Most of the mothers $(78 \%)$ were also graduates or above. Thirty two percent women were homemakers while rest were employed.

Dietary intake of subjects: Dietary intake of subjects was assessed using 24 hours dietary recall method and also by food frequency questionnaire to investigate their habitual intake of various food groups. Details are given in table 2 .

Data collected by Food frequency questionnaire revealed that primary cereals consumed were wheat and rice. Consumption of iron rich rice flakes was low. Intake of refined flour in terms of bread, pizza, magi, pasta, burgers and biscuits was very high. These items were enjoyed and were conveniently available. Millets rich in many nutrients including iron could have been consumed in form of multigrain flours but were not consumed by subjects of present study.

Consumption of whole pulses was low (Table 2). Consumption of de husked pulses was higher. Pulses were mainly consumed during dinner time. Sprouting of pulses, a technique that increases the bioavailability of iron was practiced only in $4 \%$ homes.

Most of the subjects reported having vegetables at least once daily. There was not much variety in

Table 2: Data on Food Frequency

\begin{tabular}{llllll}
\hline Food Item & $\begin{array}{l}\text { Daily } \\
\mathbf{n}(\mathbf{\%})\end{array}$ & $\begin{array}{l}\mathbf{2 - 3} \text { times/week } \\
\mathbf{n}(\mathbf{\%})\end{array}$ & $\begin{array}{l}\text { Once in a week } \\
\mathbf{n}(\mathbf{\%})\end{array}$ & $\begin{array}{l}\text { Once in 15 days } \\
\mathbf{n}(\mathbf{\%})\end{array}$ & $\begin{array}{l}\text { Not taken } \\
\mathbf{n}(\mathbf{\%})\end{array}$ \\
\hline Whole Cereals & $100(100.0)$ & $0(0)$ & $0(0)$ & $0(0)$ & $0(0)$ \\
Refined Cereals & $33(33.0)$ & $7(7.0)$ & $9(9.0)$ & $51(51.0)$ & $0(0)$ \\
Whole Pulses & $0(0)$ & $8(8.0)$ & $74(74.0)$ & $18(18.0)$ & $0(0)$ \\
De husked Pulses & $25(25.0)$ & $42(42.0)$ & $15(15.0)$ & $10(10.0)$ & $8(8.0)$ \\
Green Leafy Vegetables & $1(1.0)$ & $9(9.0)$ & $25(25.0)$ & $47(47.0)$ & $18(18.0)$ \\
Roots and tubers & $100(100.0)$ & $0(0)$ & $0(0)$ & $0(0)$ & $0(0)$ \\
Other Vegetables & $35(35.0)$ & $45(45.0)$ & $3(3.0)$ & $14(14.0)$ & $3(3.0)$ \\
Fruits & $50(50.0)$ & $40(40.0)$ & $5(5.0)$ & $5(5.0)$ & $0(0)$ \\
Milk and Milk Products & $100(100.0)$ & $0(0)$ & $0(0)$ & $0(0)$ & $0(0)$ \\
Egg & $0(0)$ & $32(32.0)$ & $23(23.0)$ & $27(27.0)$ & $18(18.0) \mathrm{M}$ \\
Meat/Chicken/Fish & $0(0)$ & $13(13.0)$ & $49(49.0)$ & $31(31.0)$ & $7(7.00$ \\
Fats and Oils & $100(100)$ & $0(0)$ & $0(0)$ & $0(0)$ & $0(0)$ \\
Nuts and oil seeds & $8(8.0)$ & $17(17.0)$ & $58(58.0)$ & $1(1.0)$ & $16(16.0)$ \\
Sugar & $100(100.0)$ & $0(0)$ & $0(0)$ & $0(0)$ & $0(0)$ \\
\hline
\end{tabular}


consumption of vegetables. Green leafy vegetables, a rich source of iron were consumed infrequently (Table 2). One reason could be that study was conducted during summers. Also some subjects reported that they or other family members did not like them. Many reported that these were not prepared at home frequently. Green leafy vegetables if consumed frequently can provide iron and many other nutrients, however their low consumption has been reported in many studies in India In a study by Kumar et al. (2006) in Allahabad, low consumption of green leafy vegetables in diets of adolescents was reported.

In the present study, subjects were from high socio economic group still only 50\% reported daily consumption of fruits. Most commonly consumed fruits were mango, water melon and musk melon. Low frequency of consumption of fruits, pulses and milk among adolescents in Ujjain, Madhya Pradesh was reported by Gowrikar et al. (2002).

In the present study all subjects were consuming milk or milk products like curd, cheese, cold coffee, butter milk etc. The amount of milk consumed varied. There was lot of variation in terms of consumption of meat/chicken/fish etc. Only $13 \%$ consumed it 2-3 times a week while others consumed it on a lesser frequency. On the other hand eggs consumption was higher. About 32\% consumed them 2-3 times a week. Mothers felt that eggs were easy to prepare and a nutritious breakfast option for children.

In the present study only $8 \%$ children were consuming nuts daily and $17 \%$ consumed $2-3$ times a week. It was reported that nuts were consumed more during winters but this study was conducted during summers and this may be the reason for low consumption of nuts. Fats were consumed daily and refined oils were mainly used as cooking medium. Some (14\%) reported consumption of pure ghee. while butter was also consumed by many $(41 \%)$ subjects. Sugar was consumed daily by all subjects for sweetening tea/coffee/milk etc. Only $26 \%$ consumed jaggery on 2-3 times a week, that also during winters. Though jaggery is a rich source of iron, it was consumed in very small quantity as a 'sweet snack' after lunch or dinner in winters only.

It was clear from the results that there were no economic constraints on subjects, but various factors like convenience, traditional practices and dietary beliefs of families influenced the dietary intake patterns of the subjects. Nutritious foods rich in iron like sprouted pulses, rice flakes, multigrain flour, jaggery etc. were not consumed. Moreover green leafy vegetables which are a rich source of carotene as well as iron and many more micronutrients were consumed in inadequate amounts due to variety of reasons like influence of season, disliked by subjects or other family members, take long time and labor in preparation etc. Fruits and nuts were also not consumed in adequate amounts.

High consumption of bread and junk foods like pizza, burger, French fries, chips and biscuits indicate to urban influences, influences of media and acceptance of ready to eat convenience foods in our life. These foods are however not providing the right nutrients as it became clear from 24 hours dietary recall analysis of their diets.

Analysis of diet by 24 hours dietary recall: Analysis of their diet in terms of energy intake revealed that calorie intake was much lower than the RDAs in all the groups and in both boys and girls. The RDA for boys in age group 10-12 years is $2190 \mathrm{Kcal}$ which increases to $3020 \mathrm{Kcals}$ for the age group 16-17 years. However in this study, the intake of energy in respective age groups increased from $1864 \mathrm{Kcal}$ to $2166 \mathrm{Kcals}$ which is quite low. Similarly in case of girls, the RDAs for the age group 10-12 years is 2010 Kcals which increases to $2440 \mathrm{kcals}$ for the age group 16-17 years. However in the present study, the intake of energy rather decreased from 1613 Kcals to 1591 Kcals in the respective age groups (Table 3).

The RDA for energy in older adolescents increases as they are young and are supposed to be physically active. However girls in this age group become highly conscious about their body image and this may be the reason for low energy intake as they do not want to become overweight. 
Table 3: Energy, Protein and iron intake of the subjects $(n=100)$

\begin{tabular}{llllll}
\hline Nutrient & Age (years) & Boys $($ Mean \pm SD) & RDA (ICMR 2010) $\begin{array}{l}\text { Girls (Mean } \pm \\
\text { SD) }\end{array}$ & $\begin{array}{l}\text { RDA (ICMR, } \\
\text { 2010) }\end{array}$ \\
\hline Energy Kcal/day & $10<=12$ & $1864 \pm 336(\mathrm{n}=18)$ & 2190 & $1631 \pm 268(\mathrm{n}=25)$ & 2010 \\
& $13<=15$ & $1915 \pm 270(\mathrm{n}=16)$ & 2750 & $1646 \pm 394(\mathrm{n}=19)$ & 2330 \\
& $16<=17$ & $2166 \pm 271(\mathrm{n}=12)$ & 3020 & $1591 \pm 385(\mathrm{n}=10)$ & 2440 \\
Protein g/day & $10<=12$ & $51.9 \pm 8.2(\mathrm{n}=18)$ & 39.9 & $51.9 \pm 9.5(\mathrm{n}=25)$ & 40.4 \\
& $13<=15$ & $57.2 \pm 9.4(\mathrm{n}=16)$ & 54.3 & $51.8 \pm 12.5(\mathrm{n}=19)$ & 51.9 \\
& $16<=17$ & $63.2 \pm 10.4(\mathrm{n}=12)$ & 61.5 & $49.9 \pm 13.2(\mathrm{n}=10)$ & 55.5 \\
Iron mg/day & $10<=12$ & $13.76 \pm 3.49(\mathrm{n}=18)$ & 21 & $12.40 \pm 6.34(\mathrm{n}=25)$ & 27 \\
& $13<=15$ & $16.59 \pm 12.51(\mathrm{n}=16)$ & 32 & $11.51 \pm 4.53(\mathrm{n}=19)$ & 27 \\
& $16<=17$ & $16.18 \pm 1.29(\mathrm{n}=12)$ & 28 & $14.23 \pm 9.24(\mathrm{n}=10)$ & 26 \\
\hline
\end{tabular}

Table 4: Nutrient Adequacy Ratio for Iron

\begin{tabular}{llll}
\hline Nutrients & $\begin{array}{l}\text { Not Adequate } \\
\mathbf{0 - 6 6} \% \text { of RDA }\end{array}$ & $\begin{array}{l}\text { Marginally Adequate } \\
\mathbf{6 6 - 1 0 0} \% \text { of RDA }\end{array}$ & $\begin{array}{l}\text { Adequate } \\
>=\mathbf{1 0 0} \% \text { of RDA }\end{array}$ \\
\hline Iron & 81 & 16 & 3 \\
\hline
\end{tabular}

In the present study, boys in all age groups were consuming more protein than the RDA. This trend was also observed in case of girls except in the age group 16-17 years (Table 3). Despite the fact that calories intake was low, diets of all subjects were cereal pulse based plus milk consumption was also sufficient to meet their protein needs. Egg consumption was also responsible for high protein intakes.

In this study, the intake of iron in all age groups ranged from 11.51-16.59 mg/day only (Table 3). This value was much lower than RDA. Low intake of iron especially among teenaged girls was reported in a study by Irwin et al. (2001). In the present study despite the fact that $69 \%$ subjects informed that they were non-vegetarians, however by 24 hours dietary recall, the consumption of heam iron rich meat sources was found to be very low. Absence or low consumption of iron rich plant foods was responsible for low iron intakes

Iron intake of subjects was further analyzed in terms of Nutrient adequacy ratio (NAR). It revealed that a very high percentage $(81 \%)$ of subjects had inadequate intake of iron. Only 16 percent had marginally adequate intake of iron and only three percent had adequate intake of iron (Table 4).

It was clear from this data that their diet was severely deficient in terms of iron intake which could have effected their hemoglobin levels and hence prevalence of anaemia.

Prevalence of anaemia among subjects: Heamoglobin assessment of all subjects was done to find out if they were anaemic or not. On the basis of WHO cutoffs they were divided as non anaemic and into different categories of anaemia. None of the subjects had severe anaemia, however mild and moderate anaemia was present in both the genders and in all age groups (Table 5).

The data reflected that severity of anaemia was more in girls than in boys. In terms of moderate anaemia it was higher in children in age group 10-12 years in comparison to older adolescents for both boys and girls. It also revealed that severity of anaemia was more in girls in comparison to boys as $59.2 \%$ girls were moderately anaemic, while $47.8 \%$ boys were moderately anaemeic. It was further decided to analyze these results in terms of knowledge, attitude 
Table 5: Age wise and gender wise prevalence of Anaemia $(n=100)$

\begin{tabular}{llllllll}
\hline Age (years) & \multirow{3}{*}{$\begin{array}{l}\text { Non Anaemic } \\
\text { Moys n (\%) } \\
\text { Mild } \\
\text { Anaemia }\end{array}$} & $\begin{array}{l}\text { Moderate } \\
\text { Anaemia }\end{array}$ & Age (years) & $\begin{array}{l}\text { Girls n (\%) } \\
\text { Mild } \\
\text { Anaemic }\end{array}$ & $\begin{array}{l}\text { Anaemia } \\
\text { Anoderate } \\
\text { Anaemia }\end{array}$ \\
\hline $10<=12(\mathrm{n}=18)$ & $3(16.6)$ & $2(11.1)$ & $13(72.2)$ & $10<=12(\mathrm{n}=25)$ & $6(24.0)$ & $1(4.0)$ & $18(72.0)$ \\
$13<=15(\mathrm{n}=16)$ & $3(18.7)$ & $5(31.2)$ & $8(50.0)$ & $13<=15(\mathrm{n}=19)$ & $2(10.5)$ & $7(36.8)$ & $10(52.6)$ \\
$16<=17(\mathrm{n}=12)$ & $4(33.3)$ & $7(58.3)$ & $1(8.3)$ & $16<=17(\mathrm{n}=10)$ & $5(50.0)$ & $1(10.0)$ & $4(40.0)$ \\
Total $(\mathrm{n}=46)$ & $10(21.7)$ & $14(30.4)$ & $22(47.8)$ & Total $(\mathrm{n}=54)$ & $13(24.1)$ & $9(16.7)$ & $32(59.2)$ \\
\hline
\end{tabular}

Table 6: Various variables related to anaemia

\begin{tabular}{|c|c|c|c|c|}
\hline Variable & $\begin{array}{l}\text { Non Anaemic } \\
23(\%)\end{array}$ & $\begin{array}{l}\text { Mildly Anaemic } \\
23(\%)\end{array}$ & $\begin{array}{l}\text { Moderately Anaemic } \\
54(\%)\end{array}$ & $\begin{array}{l}\text { Pooled Data } \\
100(\%)\end{array}$ \\
\hline $\begin{array}{l}\text { Child takes proper } \\
\text { nutritious meal }^{\text {ns }}\end{array}$ & $19(82.6)$ & $19(82.6)$ & $34(63.0)$ & $72(72.0)$ \\
\hline Child skips meals ${ }^{\text {ns }}$ & $4(17.4)$ & $4(17.4)$ & $20(37.0)$ & $28(28.0)$ \\
\hline \multicolumn{5}{|l|}{ Child takes junk food ns } \\
\hline Everyday & $2(8.7)$ & $3(13.0)$ & $5(9.3)$ & $10(10.0)$ \\
\hline Once a week & $7(30.4)$ & $5(21.7)$ & $20(37.0)$ & $32(32.0)$ \\
\hline $\begin{array}{l}\text { Use of iron utensils for } \\
\text { cooking ns }\end{array}$ & $8(34.8)$ & $2(8.7)$ & $12(22.2)$ & $22(22.0)$ \\
\hline $\begin{array}{l}\text { Active involvement of } \\
\text { child in sports } * *\end{array}$ & $20(87.0)$ & 16(69.6) & $9(16.6)$ & $45(45.0)$ \\
\hline Child feels lethargic * & $0(0)$ & $1(4.3)$ & $8(16.7)$ & $10(10.0)$ \\
\hline
\end{tabular}

Chi square test, $n s=$ non-significant, ${ }^{*} p<=0.5 ;{ }^{* *} p<=0.1$.

and practices of subjects and their parents that may have influenced presence of anaemia.

Assessment of various factors in relation to Anaemia: It was clear from the study that dietary intake of iron was extremely low by subjects in the present study. It was attempted to find other reasons behind prevalence of anaemia and its implications. Some of the factors studied are given in Table 6. An attempt was made during the study to understand the knowledge, attitude and practices of parents/subjects and to find its relationship with prevalence of anaemia. As reported by parents their children were consuming nutritious meals in $72 \%$ cases. The incidence of consuming improper meals was reported higher in children having moderate anaemia as compared to non-anaemic group $(37 \% \mathrm{v} / \mathrm{s}$ $17.4 \%)$. However, this difference was not found to be statistically significant as tested by chi-square. This could be due to reason that parents themselves were

not aware that child's diet was deficient in iron or the child was anaemic.

It was seen that $37 \%$ adolescents of moderate anaemia category, irrespective of gender were in habit of skipping meals. Generally breakfast was skipped as they reported that there was no time for breakfast during school days. The difference between groups were non- significant Skipping of meals by adolescents was also reported in a study in Taiwan (Story et al. 2003).

Ten percent of subjects were consuming junk foods daily while 32 percent were taking them once a week. Rest of them were taking these at lower frequency. The differences in different groups were non-significant. Reliance on convenience foods and poor eating habits of European teenagers have been reported in a study by Hackett and Gibbon (2002).

Use of iron utensils was $34.8 \%$ and $22 \%$ in non anaemic and moderately anaemic groups respectively. These 
differences were found to be non-significant. Only $8 \%$ parents knew that using iron karahi can increase the iron content of food.

It was found that $45 \%$ children were actively involved in sports activities at school, the non anaemic group $(87 \%)$ being most involved. Those who were not involved in any kind of physical activity were mostly engaged in watching television, followed by studies and rest preferred internet surfing. Only 16.6\% moderately anaemic subjects participated regularly in sports. This difference was found to be statistically significant as tested by chi square. The results clearly brought out the fact that moderately anaemic subjects did not have the stamina to regularly participate in sports.

Further $10 \%$ children were reported to be lethargic by their parents. This prevalence was higher (16.7\%) in moderately anaemic group while none of the parents of non anaemic children reported that their child was lethargic. This difference was statistically significant as tested by chi square. This fortifies the role of anaemia in decreasing the physical capacity of an individual and making him lethargic.

From findings of this study it is concluded that there is prevalence of anaemia in adolescents in high socio economic strata despite no constraints in affordability. This highlights need to make healthy choices for which nutrition education is imperative. Further poor nutrient intake among the study group especially in terms of energy and iron highlight immediate needs for nutritional counselling which can address these problems.

\section{REFERENCES}

Deepa, K.S., Pushpabharati and Kasturiba, B. 2004. Seasonal variation in iron status of adolescent girls in Dharwad Taluk. J. Human Ecology, 15(3): 175-178.

Gowarikar, R., Gawarikar, S.B. and Tripathi B.C. 2002. Prevalence of anaemia in adolescent girls of Ujjain in western M.P. Indian J. Nutr. And Dietetics, 39: 493-498.

Hackett, A.F., Gibbon, M. and Sratton, G.M. 2002. Dietary intake of adolescents in Liverpool. Public Health Nutrition, 5: 499-455.

Kirchner, I. 2001. Anaemia in children American Family Physician, $15 ; 64(8)$

Kakkar, R., Kakkar, M., Khandpal, S.D. and Jethani, S. 2005. Study of anaemia in adolescent school girls of Bhopal. The Indian Journal of Community Medicine, 31(4): 155-158.

Kumar, A.R., Yadav, N., Gupta, A.K. and Verma, V. 2006. Influence of family's vegetable cultivation on prevalence of anaemia among adolescent girls. The Indian Journal of Nutrition and Dietetics, 40: 147-152.

Prabhakaran, 2003. Nutritional status of adolescent girls residing in a university hostel. The Indian J of Nutrition and Dietetics, 40:274-279.

Story, M., French, S.A. and Resnick, M.D. 2003. Socioeconomic differences in dieting behaviors and body image perceptions in adolescents. J. Eating Disorders, 18: 1739.

World Health Organization, 2001. Haemoglobin concentrations for the diagnosis of anaemia and assessment of severity. 